
allemande

50-2 | 2018

Humanités environnementales - Quoi de neuf du côté des méthodes?

\title{
Le sacrifice du sauveur? Mort et transfiguration de Gustave Adolphe de Suède dans la propagande protestante de 1632 à nos jours
}

Frank Muller

\section{CpenEdition}

Journals

Édition électronique

URL : https://journals.openedition.org/allemagne/971

DOI : 10.4000/allemagne.971

ISSN : 2605-7913

Éditeur

Société d'études allemandes

Édition imprimée

Date de publication : 30 décembre 2018

Pagination : 395-414

ISSN : 0035-0974

Référence électronique

Frank Muller, «Le sacrifice du sauveur? Mort et transfiguration de Gustave Adolphe de Suède dans la propagande protestante de 1632 à nos jours », Revue d'Allemagne et des pays de langue allemande [En ligne], 50-2 | 2018, mis en ligne le 30 décembre 2019, consulté le 20 mai 2021. URL: http:// journals.openedition.org/allemagne/971 ; DOI : https://doi.org/10.4000/allemagne.971 


\section{Le sacrifice du sauveur? Mort et transfiguration de Gustave Adolphe de Suède dans la propagande protestante de 1632 à nos jours}

- Frank Muller*

\section{Diß ist der Mann der helfen kann}

La mort dramatique de Gustave Adolphe à la bataille de Lützen le 6/16 novembre $1632^{(1)}$ a engendré très vite après sa mort un flot de prêches et de feuilles volantes mettant en valeur sa qualité d'envoyé de Dieu pour sauver la "vraie» religion et son sacrifice. En fait, avant même son débarquement à Peenemünde, sur l'île d'Usedom, en Poméranie, une campagne de propagande par l'écrit et par l'image s'était mise en place en Allemagne, notamment à partir de Hambourg, ville de la Hanse restée neutre parce que non menacée encore par l'avancée des troupes impériales. Ce flot de feuilles volantes a souvent été analysé et reproduit ${ }^{(2)}$, mais avant d'en examiner quelques-unes parues après la mort du roi, il faut revenir un instant sur la très ancienne discussion sur les buts de guerre de Gustave Adolphe, qui a depuis longtemps oscillé entre les interprétations confessionnelles mettant en avant la volonté de sauver le protestantisme allemand et celles qui pointaient l'esprit de conquête du roi et sa volonté de faire de la Baltique un «lac suédois» protégé par des possessions en Allemagne du Nord ${ }^{(3)}$. En réalité, ainsi que l'énonçait clairement Michael Roberts, les aspects politiques et religieux ne peuvent être séparés:

* Professeur émérite d'histoire moderne, Université de Strasbourg.

1 Cette double datation résulte du fait que les protestants continuèrent pendant assez longtemps à utiliser le calendrier julien, alors que les catholiques étaient déjà passés au calendrier grégorien. De façon symbolique, les grands moments commémoratifs des $\mathrm{XIX}^{\mathrm{e}}$ et $\mathrm{XX}^{\mathrm{e}}$ siècles ont toujours eu lieu le 6 novembre.

2 Voir surtout les ouvrages de W. Harms et de J.R. Paas cités en bibliographie, mais beaucoup de ces feuilles volantes ont été reproduites dans les nombreux ouvrages consacrés à la guerre de Trente Ans.

3 Bonne synthèse du contexte politico-idéologique (hors religion), in: Johannes BuRkHARDT, Der Dreißigjährige Krieg, Francfort-sur-le Main, Suhrkamp, 1992, p. 51-63, et de la question religieuse, p. 128-143. 
"In the world of the early seventeenth century the two could scarcely be dissociated. Politics were to a large degree influenced by religion; the cause of religion was sustained by political weapons. Gustavus Adolphus was neither a single-minded Protestant Hero, nor a ruthless Realpolitiker: he was both» ${ }^{(4)}$.

Dans ses ouvrages très stimulants, mais quelque peu hagiographiques, Günter Barudio le présente même comme le héros du droit, défenseur des "libertés germaniques", et son interprétation se fonde sur des sources précises, même si là encore il est difficile de dissocier sincérité et Realpolitik. Mais le fait d'intituler le chapitre sur Lützen «Lützen - ein letztes Leiden» et d'y inclure l'image du pélican se saignant pour ses petits, sur laquelle je reviendrai, montre bien que l'auteur, à juste raison d'ailleurs, ne dissocie pas le politique et le religieux.

Quoi qu'il en soit, il ne sera question ici que des aspects religieux, d'autant que ce n'est tout de même pas un hasard si le flot propagandiste évoqué plus haut se fonde constamment sur la Bible et plus précisément sur l'idée d’un envoyé de Dieu pour sauver le protestantisme en Allemagne ${ }^{(5)}$, qu'il soit qualifié de nouveau Moïse, de Josué, de Gédéon, de Samson, de Judas Maccabée ou aussi de nouveau roi Josias, destructeur des idoles, i. e. du catholicisme, et allié des Assyriens contre le pharaon, donc ici allié des Allemands contre l'empereur ${ }^{(6)}$. Ces comparaisons vétérotestamentaires montrent combien, aux heures de lutte, le protestantisme militant se voit comme nouvel Israël, aussi bien dans la lutte des Provinces-Unies contre l'Espagne que dans celle, malheureuse, des États de Bohême contre l'absolutisme de Ferdinand II et plus tard dans la résistance des Camisards contre les troupes de Louis XIV. Or il se trouve qu'incontestablement à cette époque, le protestantisme dans l'Empire était réellement menacé: l'Édit de restitution de 1629 visait explicitement à déposséder les États protestants de leurs acquisitions postérieures à la paix d'Augsbourg de 1555. Il suffisait de contempler la situation dans les pays héréditaires ou pseudo-héréditaires des Habsbourg, c'està-dire l'Autriche et les États de la Couronne de Bohême, où la «Constitution renouvelée» de 1627 dépouillait pratiquement les diètes de leurs prérogatives, après que le catholicisme, très minoritaire, ait été rétabli par la force après la Montagne-Blanche (1620). Cette situation explique aussi que les «frères ennemis » luthériens et calvinistes se soient unis, après bien des hésitations pour certains, derrière la bannière de Gustave Adolphe, les derniers nommés, notamment le malheureux «roi d'un hiver», l'ex-électeur palatin Frédéric V, et Guillaume V de Hesse-Kassel, étant plus immédiatement intéressés par un retournement de situation en leur faveur. Le grand nombre de soldats

4 Michael Roberts, Gustavus Adolphus, Londres/New-York, Longman, 1973 (2 éd.), p. 46.

5 Hellmut Zsсносн, "Größe und Grenzen des "Löwen von Mitternacht” ", Zeitschrift für Theologie und Kirche, Tübingen, 91 (1994), cahier 1, p. 25-50, ici p. 28-29, particulièrement note 14, montre très justement à mon sens que cette propagande, aussi exagérée et problématique qu'elle puisse être considérée aujourd'hui, s'accordait à la mentalité et aux espoirs des protestants de l'époque.

6 On peut d'ailleurs remarquer que fort peu de feuilles volantes et d'écrits polémiques mettent directement en cause Ferdinand II et Maximilien de Bavière, les deux principaux responsables du début de la guerre et de son prolongement. Même s'il faut tenir compte du financement partiel de l'armée suédoise par la France catholique, cela montre entre autres qu'il ne semble guère avoir été question pour le roi de Suède de se faire élire empereur, comme nombre de contemporains et d'historiens postérieurs le supposaient. 
anglais et écossais dans les rangs «suédois", le soutien à la fois financier et militaire des Provinces-Unies - aux prises avec les troupes du stadhouder Frédéric Henri, les Espagnols ne pouvaient guère intervenir dans l'Empire - montrent la réalité de l'union politico-religieuse derrière le «Lion de Minuit», qui, selon des prophéties chiliastes venant notamment des milieux paracelsiens et rosicruciens, devait vaincre enfin l'Antéchrist, i.e. l'Église romaine, d'où l'abondance dans les feuilles volantes de propagande du motif de la Bête apocalyptique, associée depuis les débuts de l'imagerie polémique de la Réforme à la Prostituée de Babylone coiffée de la tiare papale. De plus, le roi, depuis son débarquement, avait toujours dit qu'il respecterait le culte catholique, ce qui fut le cas notamment après la conquête de deux hauts lieux du catholicisme, Mayence et Munich, où le souverain assista même à une messe, le paradoxe étant qu'en Suède, les calvinistes étrangers étaient tolérés, mais les catholiques impitoyablement poursuivis, les dirigeants suédois craignant toujours un retour offensif du catholicisme porté par la branche polonaise des Vasa.

Dans toute cette littérature de propagande, Gustave Adolphe est constamment présenté comme l'Envoyé du Très-Haut et parfois même comme le Messie (sic!), ceci est souvent visualisé par la main de Dieu tendant le glaive au roi, selon les paroles de Jérémie à Judas Maccabée: «Prends ce glaive saint, il est un don de Dieu et avec lui tu briseras les ennemis» (II Mac. 15,16) ou simplement par des rais de lumière qui tombent sur lui. Certaines feuilles font plus ou moins explicitement la comparaison avec le Christ, se servant notamment du jeu de mots Sued/Deus. Une autre, intitulée Königlicher Majestät zu Schweden.../ von GOtt zugeordnete/ Englische Wagenburg (Un rempart de chariots organisée par Dieu pour le roi de Suède) ${ }^{(7)}$, presque entièrement constituée de citations bibliques, montre des anges protégeant le roi en prières par des chariots, des roues et un bouclier, tandis que d'autres chassent les soldats ennemis, déjà menacés par un violent orage. Au premier plan gisent au sol de part et d'autre des masques et un serpent coiffé d'un bonnet de jésuite symbolisant la fausseté du parti adverse. Levant les yeux vers le ciel, le roi y voit une croix scintillante d'où partent les mots fameux de la «vision de Constantin»: "In hoc signo vinces", incitant ainsi le croyant à la prière pour le roi et la cause du protestantisme.

Plusieurs feuilles relatent la prise d'Augsbourg par les Suédois, épisode d'une grande importance symbolique pour les protestants et plus spécifiquement pour les luthériens, la Confession d'Augsbourg ayant été présentée à Charles-Quint en 1530. Ce n'est évidemment pas un hasard si Gustave Adolphe a débarqué en Allemagne le jour même (dans le calendrier julien) du centenaire de cet événement, au moment où le protestantisme allemand était au plus bas. De plus, Augsbourg avait été occupée depuis plusieurs années par les troupes bavaroises, qui avaient mis les catholiques à la tête de la ville, alors que la majorité de la population était protestante et quauparavant la cohabitation s'était relativement bien passée pendant des décennies. Dans la polémique protestante à ce sujet, le roi de Suède combattait là encore l'Antéchrist, sous la forme principale de Jésuites, traités généralement de jesuwider (littéralement:

7 Repr. Paas - 1627. Repr. et commentaire par Michael Schilling, in: Um Glauben und Reich. Kurfürst Maximilian I., catalogue d'exposition sous la dir. de Hubert Glaser, Wittelsbach und Bayern II, 2, Munich, 1980, p. 400, nº 639. 
ceux qui sont contre Jésus) et détestés en tant que fer de lance de la Contre-Réforme, comme l'avaient été les dominicains et les franciscains un siècle plus tôt. Dans la plus intéressante de ces feuilles l'Augusta angustiata (Augsbourg angoissée) sous la forme d'une femme à terre voit apparaître son libérateur, lequel lève ses yeux vers le ciel où brille le Tétragramme et qui est désigné comme étant «der Mann der helfen kann» (L'homme qui peut aider ${ }^{(8)}$ ), d'où mon titre.

Plus explicites encore, certaines feuilles volantes étaient conçues pour être accrochées chez soi afin de pouvoir leur adresser des prières; l'une d'elles, qui porte un titre double et fort explicite: Salutatio quotidiana/ intuentis/ regiam effigiam et Täglicher Gruß/In anschawung/ Deß Königlichen Bildnuß (Salutation quotidienne en regardant le portrait du roi) ${ }^{(9)}$, se compose du portrait du roi, puis d'une prière en latin dans la colonne de gauche et en allemand dans la colonne de droite, qui recommande à chacun de faire chaque matin une prière pour le héros protégé par Dieu. On est là dans le cas de figure de la prière d'intercession des catholiques à l'adresse des saints et certains pamphlétaires catholiques ne se sont pas fait faute de le souligner ironiquement ${ }^{(10)}$. Le dernier quatrain de cette prière est particulièrement intéressant:

«Sey auff, und schlag sie auß dem Land

Durch Gottes Macht und starcke Hand

Schaff Fried und Freyheit in dem Reich

Dein ist Scepter und Cron zugleich» ${ }^{(11)}$.

Le dernier vers doit évidemment s'interpréter comme une invite à se faire proclamer empereur, mais l'auteur a pu aussi, fût-ce inconsciemment, penser à la couronne du martyr, chacun sachant que le roi s'exposait dans les combats.

\section{In regem non mortuum}

Très vite après que la mort du roi ait été confirmée (il y a eu des rumeurs pendant quelque temps, mais pas de confirmation officielle; Wallenstein lui-même n'a vraiment été convaincu du décès de son adversaire que fin novembre), les réactions de l'Allemagne protestante ont été amples et unanimes, en particulier dans les villes libres qui avaient accueilli leur héros avec effusion: Augsbourg, Francfort, Nuremberg, etc., mais aussi dans les territoires princiers, en particulier en Saxe, même si l'électeur de Saxe, Jean-Georges, le «Bierjörge», ne s'était allié que par contrainte au roi de Suède et ne mit guère de temps après la mort du roi à reprendre ses tractations avec l'empereur.

8 Cf. H. Zsсносн, «Größe und Grenzen des "Löwen von Mitternacht” (note 5), p. 35.

9 Paas - 1551. Repr. et commentaire par M. Schilling, in: Um Glauben und Reich (note 7), p. 398, $\mathrm{n}^{\circ} 634$.

10 Il y a au moins un exemple antérieur comparable dans le luthéranisme, c'est celui du fameux portrait de Luther à la colombe du Saint-Esprit, par Hans Baldung Grien (1521), dont une dépêche à la curie du nonce Aleander, délégué du pape à la diète de Worms, nous apprend que les gens «l'achètent, l'embrassent et vont jusqu'à l'emporter dans le palais impérial». Voir à ce sujet, Frank MuLLER, Images polémiques, images dissidentes. Art et Réforme à Strasbourg (1520-vers 1550), Baden-Baden, Koerner, 2017, p. 49-55.

11 (Lève-toi et chasse les du pays/ Par la puissance de Dieu et sa forte main/ Apporte la paix et la liberté dans l'Empire/ Le sceptre et la couronne sont à toi.) 
À Strasbourg par exemple, l'émotion, au moins officielle, fut vive: le 9 décembre 1632, de nombreux cultes dans les sept églises paroissiales furent célébrés à sa mémoire et on ne s'étonnera pas que les pasteurs se réfèrent une fois encore à Judas Maccabée, au roi Josias, tout cela accompagné de psaumes et de chorals. Encore un an après la mort de Gustave Adolphe, à la demande du chancelier Oxenstierna, trois jours d'hommages cultuels furent décrétés, car selon le texte du Magistrat le roi avait donné sa vie «für das allgemeine Evangelische Wesen, und zur erhaltung der Teutschen Freyheit» (pour le protestantisme dans son ensemble et pour la sauvegarde des libertés allemandes). On remarquera qu'une fois de plus le politique et le religieux sont associés. Mais c'est surtout à travers les feuilles volantes et les écrits de circonstance rédigés soit en latin, soit en allemand par les lettrés locaux, Bernegger, Becht, Freinsheim, Gloner, etc., qu'on peut prendre la mesure de l'importance de l'événement, fût-ce au prix d'un lyrisme ampoulé courant à l'époque ${ }^{(12)}$. La notion de sacrifice est évidemment omniprésente et on relève parfois des comparaisons affirmées ou discrètes avec le sacrifice du Christ.

Faute de pouvoir analyser tous ces hommages, où la survie symbolique du souverain est souvent réaffirmée (d'où le titre de cette partie, qui est tiré d'une de ces feuilles volantes), il suffira de considérer trois de ces témoignages, un peu postérieurs, qui montrent que contrairement à ce qui est parfois affirmé, le souvenir de ce que les protestants considéraient comme la mission du roi est resté vivace au moins jusque vers la fin des années 1630, même si assez rapidement la guerre devenue vraiment européenne ne se préoccupait plus guère de religion.

La première feuille, qui date de 1633 , a un titre programmatique, puisqu'elle s'intitule Der Schwede lebet noch (ill. 1) ${ }^{(13)}$. Ce titre est évidemment à prendre au sens symbolique et veut inciter les protestants à continuer le combat. Cette allégorie assez élaborée et visuellement frappante est explicitée par le texte en vers allemands qui l'accompagne et qui est un bel exemple de la poésie baroque de l'époque. Des personnifications de l'Antiquité: Famose (Fama), Mnemose (Mnemosyne) et les muses Uranie et Melpomène, ainsi que la Sulamite, dialoguent en passant de la lamentation funèbre de "notre Samson», de «notre "Maccabée», qui «a vaincu dans la mort même», à une exaltation joyeuse, car "le Suédois vit encore», expression plusieurs fois répétée et qui termine le texte. Vainqueur symbolique de la mort, le héros se dresse sur un rocher central flanqué de deux autres, chacun ceint d'une couronne (Tre Kronor, qui figurent sur les armoiries royales suédoises). Sur le rocher de gauche se tient un écu aux armes de Suède, sur celui de droite les armes de l'électorat de Saxe (la feuille a probablement été fabriquée en Saxe). Gustave Adolphe tient d'une main le bâton de maréchal et de l'autre une épée dans laquelle

12 Sur tout ce contexte strasbourgeois, voir le mémoire de master dactylographié de Pierre KRIEGER, La ville libre d'Empire de Strasbourg et la Suède de Gustave II Adolphe durant la guerre de Trente Ans: négociations, alliance et propagande (1631-1633), Université de Strasbourg, Faculté des Sciences historiques, 2014, p. 242-270 et annexes 6-20 et 28-30.

13 Repr. et commentaires, in: Wolfgang Harms (éd.), Deutsche illustrierte Flugblätter des 16. und 17. Jahrhunderts II: Die Sammlung der Herzog August Bibliothek in Wolfenbüttel, Bd. 2: Historica, Munich, Verlag Kraus, 1980, p. 305. 


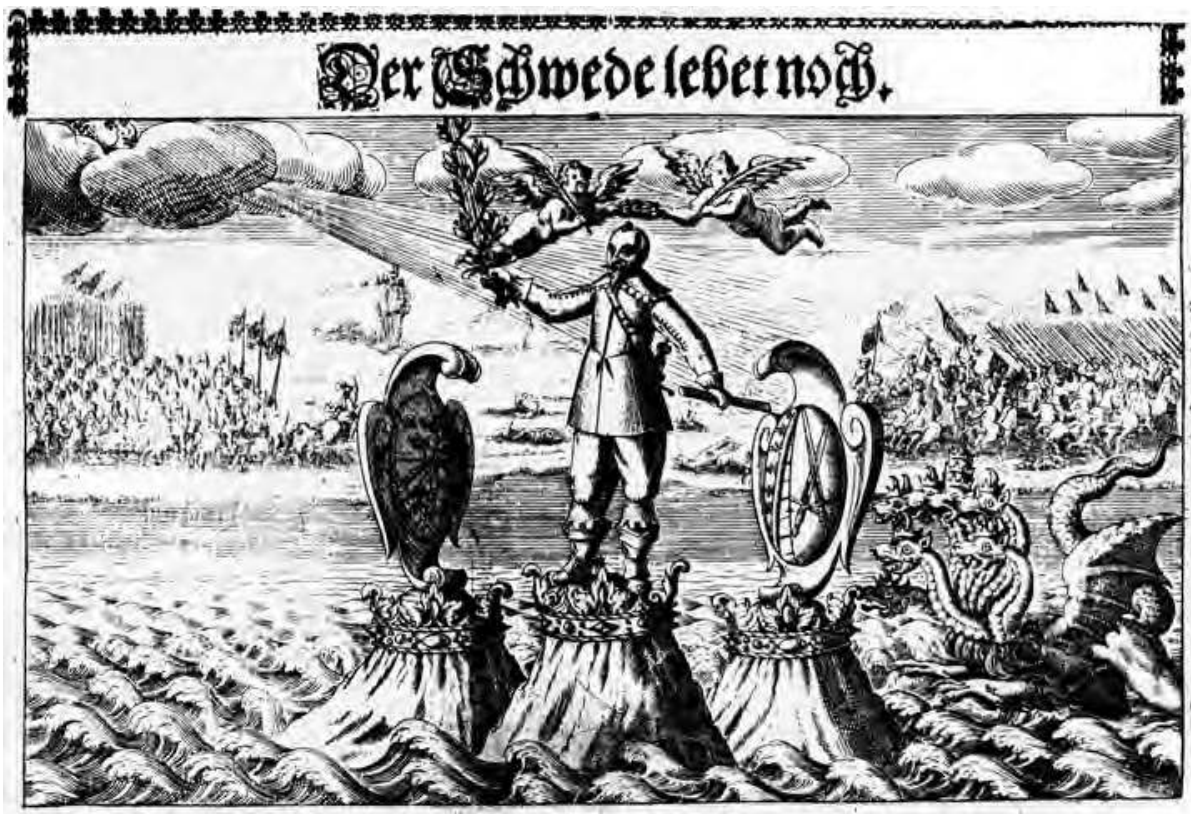

\section{Traiberpoftet.}

Die wefsmutige poftmesteren Fraw FAM OSE.

forgeaget/ Haget aflibr Frommen/ 1. 2in ber Elbe/Pleie vio Gaal/ Dner Simion in umbtommin. Staget / flaget aflummal. 2Beb! D web ber grofien Morb! 28 b' D web oer Sdowed if $100 /$

2nier Joffen/Eiedtet vno Qeben Sar ben eblen beift auffigeben.

Die Graw Uranofe, die Simmel623argetit. Thr Tddeter an oer Saal//br $\$$ inber an ber Elbel

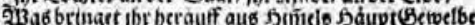

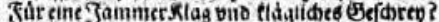
2lis ob co inic cud auఠ/ond ganizveriobren fey.

Die Fraw Sulamitin; bie Sprriftide STlage. Dhutter.

28nfer Maccabeer figet Ini firgbaffen Dfter'stib/

Der im Tobe nod) fieget/ Nimmet mit fid aus ber Wett

2liten Sleg/ ono alles (blüd) 2ille grbet nun zurìd!

Raub pino Beute/ Eano vilo Seute/ Sallen auff ber Serinbe Scite:

Die Sraw Melpole; die ZroffSs? efferint: Der Sdrtweor lebee nody ono mirb fo langs leben/ gis er ben Earaus bat oemp abet onop pabfruñi geben. Des jautset alle 2 belt /uno wer bom 2 abslojods Befreves/ruffet aus: Der Sdatrebe lébetnod,

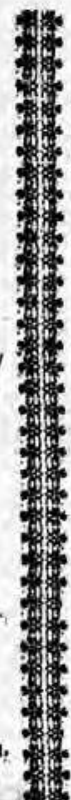

Fretwben $P_{0}$.

Die wandelmutrbige poftmeifferin Staw EAMOSE,

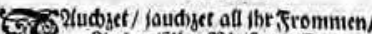

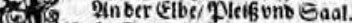

Onfres sdiveb iff twieder tommen/ Saudiset//4audbet allisumal.

Jaudzet/ laudser Sfimmel bods

2Inier Edivese leber nod:

Bnfer horfen/ Riectir bno Qebea/ 23ird vas Fried und Trenhelt geben.

Die Sraiv Mnemofe; bie Gebendedeifterin. Der Sdmecoe lebet nodano no iro fo lange leben/

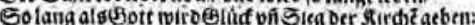

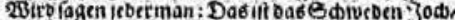

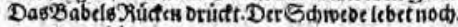

Die Statw SFedutilDe/Die Sseldenmeifterin. 2infer Doraccabeer flebet

Imifiegbafiten Sod)(an Feto/

Qnb nod) inmer tweticer gebet

Durdo bie ganize Deuríse 28 tif.

gauter ellit vino lauter Sieg Solger ibm uno isénein Srieg.

Raub ono 2 cute Land vno Qeute

Fallen all auff féne Sritt.

Die Fran Uranofe; Die Syiummels Birgetin, Der Sdivebelebet nod/ bno wiro audereigleben!

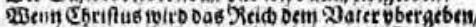
2Biro ruffen alle Wielt: Dalligec Babels Jod Intisfen Seltempful, Der Edwebelebernod. 
s'entrelacent des rameaux d'olivier, le désignant ainsi comme maître de la paix et de la guerre. Comment ne pas songer là à la représentation courante du Christ du Jugement dernier, de la bouche duquel sortent une épée pour juger les méchants et un rameau d'olivier pour apporter la paix aux bons? Au-dessus de lui, deux anges brandissant des palmes et une couronne lui confèrent à la fois l'aura du vainqueur et celle du martyr. On est là, une fois encore, dans une histoire du Salut à peine laïcisée, d'autant qu'en haut à gauche une figure céleste souffle un vent divin qui met en fuite l'armée de l'Antéchrist symbolisée par l'inévitable bête à sept têtes d'Apocalypse 17, une des têtes portant la couronne papale. Cette fusion du terrestre et du divin peut être illustrée par deux extraits du texte: «Der Schwede lebet noch und wird so lange leben/ Bis er den Garaus hat dem Pabst und Pabstum gegeben» (Le Suédois vit encore et vivra/ jusqu'à ce qu'il ait occis le pape et la papauté) et «Der Schwede lebet noch und wird auch ewig leben/ Wenn Christus wird das Reich dem Vater übergeben» (Le Suédois vit encore et vivra éternellement/ quand le Christ aura remis le Royaume à son Père [c'est-à-dire après le Jugement dernier]). Les efforts du chancelier Oxenstierna pour reconduire l'alliance des protestants allemands dans la Ligue de Heilbronn, qui date de la même année, sont donc sublimés, si l'on peut dire, dans cette allégorie qui l'inscrit dans la lutte contre le Mal; le «Suédois qui vit encore» doit donc être compris comme, au-delà même de la personne du héros, la survivance du «Bon combat» mené par la Suède. On remarquera d'ailleurs que rien, ni dans le texte, ni dans l'image, ne fait précisément allusion à l'ennemi véritable, c'est-à-dire l'empereur et la Ligue catholique, mais il était facile de comprendre qu'il s'agissait aussi d'une lutte réelle.

Une feuille plus tardive, datant probablement du printemps 1636, et rédigée en néerlandais (il est probable, vu le sujet, qu'il y ait eu une version antérieure en allemand), Droom - Spoock, Ofte des Koninghs van Swedens Geestes (Le fantôme vu en rêve, ou l'esprit du roi de Suède) (ill. 2). Probablement éditée à Utrecht et illustrée par un des bons graveurs néerlandais de l'époque, Crispijn de Passe le Jeune, elle proviendrait de la chancellerie royale suédoise (ce qui paraît douteux quand on lit le texte), car il est indiqué qu'elle a été "gedruckt voor den Svveetschen Autheur, Anno 1636» (imprimé pour l'auteur suédois en 1636), auteur qui intervient luimême dans le texte pour conclure. Il s'agit certainement d'une des feuilles les plus originales de la polémique de l'époque: l'image comme le texte me paraissent d'une inspiration shakespearienne évidente (on songera par exemple aux visions qui apparaissent à Richard III avant la bataille de Bosworth). L'intention est clairement politique, on le verra, mais visualisée de façon très particulière. Il s'agit en effet de stigmatiser la paix de Prague, signée en mai 1635 entre l'empereur et la plupart des princes luthériens, à l'exclusion des calvinistes et de la Suède. Elle est visualisée par le banquet de l'arrière-plan à gauche, qui pourrait faire penser au festin de Belshatsar (Balthazar) décrit en Daniel 5, où une inscription de feu indique au roi sa fin prochaine.

Le fantôme de Gustave Adolphe apparaît en rêve à l'électeur de Saxe, qui dort coiffé de sa couronne, et le somme de se réveiller au sens littéral et figuré du terme (Ontwaeckt! ontwaeckt! ontwaeckt! est-ce un hasard si ces trois mots qui débutent 


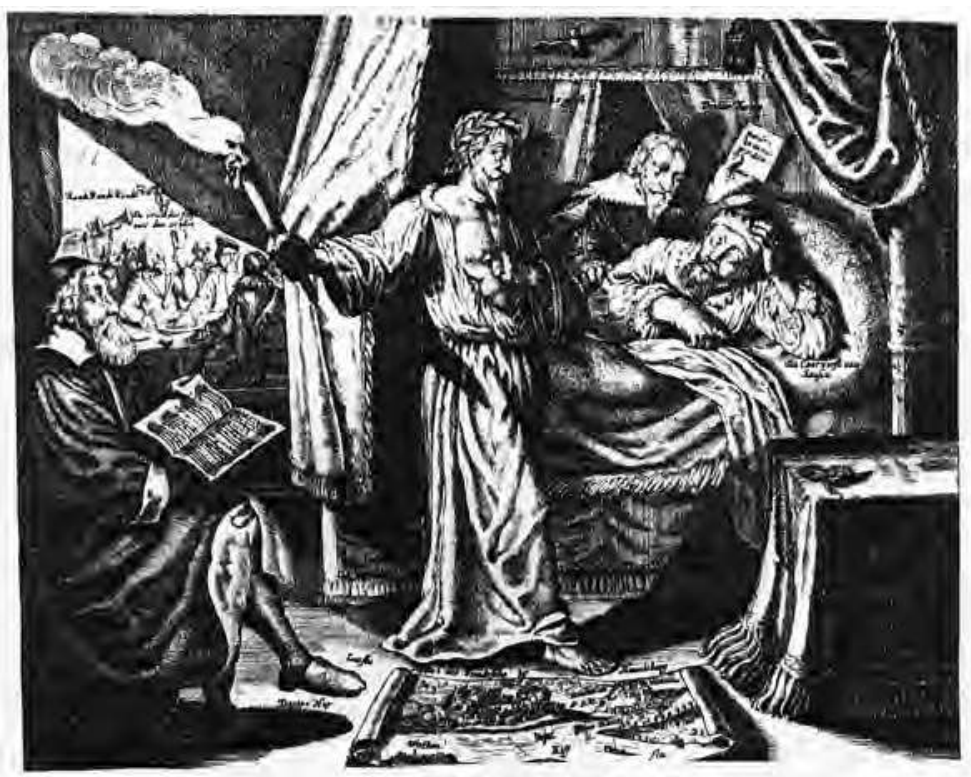

77 DROOM-SPOOCK,

Ofre des Koninghs ran Swedens Geeftesaen-fpraeek aen den Keur-vorftvan Saxen, san veghen de Verbondes beecting be, des Leas 6 Jf. dea 20. Mcy,
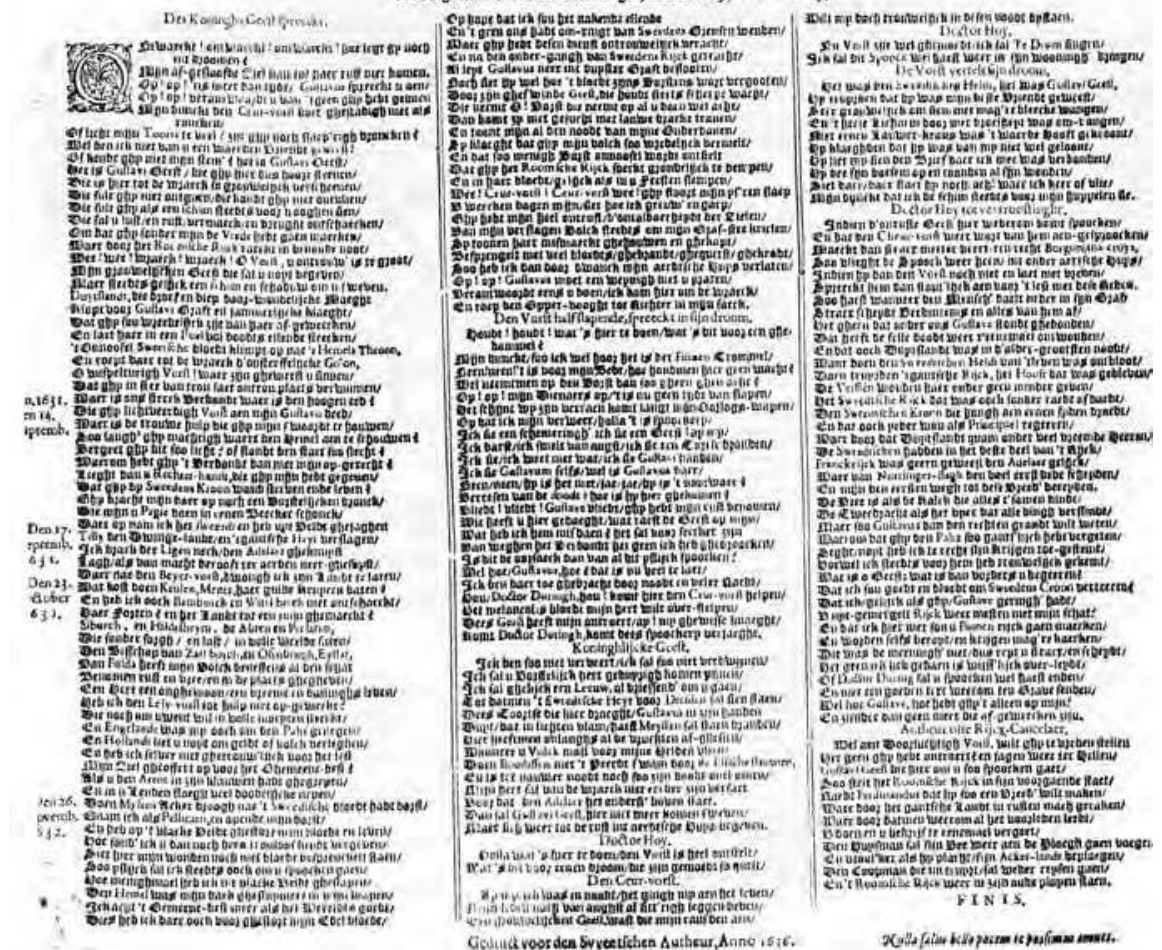

Ill. 2: Droom Spoock (Hessischen Landes-und Hochschulbibliothek Darmstadt). 
l'exhortation de Gustave Adolphe font penser au coq qui chante trois fois lors du reniement de saint Pierre ?). Il lui rappelle leur alliance passée et toute sa campagne, en évoquant son sacrifice à Lützen, tel le pélican, symbole qu'on retrouvera dans l'exemple suivant, et la dernière victoire des Suédois sur les Saxons à Havelberg en Brandebourg en décembre 1635 (visualisée par la carte de la bataille au pied du lit, comme s'il s'agissait d'une carpette), en menaçant avec sa torche de porter à nouveau le feu en Saxe, ce qui sera d'ailleurs réellement le cas plus tard. Un des conseillers de l'électeur et négociateur de la paix, le docteur During, semble se repentir de son action, brandissant un papier portant l'inscription "pardon en immer pardon", alors que le personnage assis à gauche et tenant un livre de cantiques, Dr. Hoy, c'est-à-dire Matthias Hoe von Hoenegg, prédicateur de cour de l'électeur et depuis longtemps partisan de la paix avec l'empereur, invoque la sincérité de l'alliance, mais aussi les circonstances qui ont changé, la dévastation du pays, etc. Curieusement le soi-disant auteur suédois fait montre d'esprit d'ouverture, semble l'appuyer et demande à l'électeur d'user de son influence (des plus problématiques dans la réalité) sur l'empereur pour qu'il restaure l'Empire dans son état antérieur. Une dernière allusion biblique et non des moindres me paraît être le geste du fantôme indiquant de sa main gauche la blessure de son flanc droit: le spectateur de l'époque pouvait difficilement ne pas penser au «coup de lance» donné à Jésus par un soldat (Jean 19).

Il faut enfin dire quelques mots d'un ouvrage rarement commenté, celui d'un pasteur néerlandais, Bartholomaeus Hulsius, complété et illustré lui aussi par Crispijn de Passe le Jeune. Le livre, intitulé Den onderganck des Roomschen Arents door den Noordschen Leeuw (L'aigle romain vaincu par le lion du Nord) est paru à Amsterdam en 1642 (Hulsius était déjà décédé à l'époque) et se présente sous la forme d'un livre d'emblèmes à la gloire de Gustave Adolphe, chaque image étant commentée par quatre quatrains ${ }^{(14)}$. La page de titre montre, de part et d'autre du titre, Gustave Adolphe brandissant son épée à gauche et une femme en noir (Desolata Germania) désignant des cadavres d'enfants mutilés gisant devant elle. Dans le haut de l'image, la Renommée souffle dans une trompe et brandit le Chapeau symbole de la Liberté (Patria Libertas); on peut remarquer à ce propos qu'il s'agit d'un symbole lié à la lutte des Provinces-Unies (on le trouve par exemple dans le monument funéraire de Guillaume d'Orange dans la Nieuwe Kerk de Delft) et qu'à ma connaissance on ne trouve guère en Allemagne, preuve qu'un certain nombre de contemporains se rendaient compte qu'il s'agissait bien d'une guerre européenne. Dans le corps du texte, la plupart de ces images sont allégoriques, mais d'autres se réfèrent à des événements historiques réels: ainsi la treizième représente le roi mort, avec la bataille de Lützen à l'arrière-plan (ill. 3). Un rayon lumineux venu du ciel illumine son visage, alors que sur un rocher à gauche se trouve un pélican nourrissant ses petits de son sang, claire allusion au sacrifice du monarque. Dès les premiers siècles du christianisme, puis au Moyen Âge, à partir notamment du Physiologus, le pélican symbolise le sacrifice du Christ, mais aussi sa résurrection. Quand on sait que nombre d'illustrations antérieures le placent au-dessus du Crucifié, l'assimilation du sacrifice

14 Voir commentaire et repr. de la page de titre, in: Ilja M. Veldman, Crispijn de Passe and his Progeny (1564-1670). A Century of Print Production, Rotterdam, Sound \& Vision Publishers, 2001, p. 334-337. 
du roi à celui du Christ ne peut que venir à l'esprit du lecteur de l'époque. D'autre part, Hulsius était un prédicateur contre-remontrant, c'est-à-dire calviniste intransigeant, et de Passe venait d'une famille mennonite, deux confessions qui a priori avaient quelques raisons d'avoir peu de sympathies pour les luthériens, mais comme évoqué plus haut les différences confessionnelles intra-protestantes étaient en train, non de disparaître, mais de s'estomper provisoirement face à un ennemi commun.

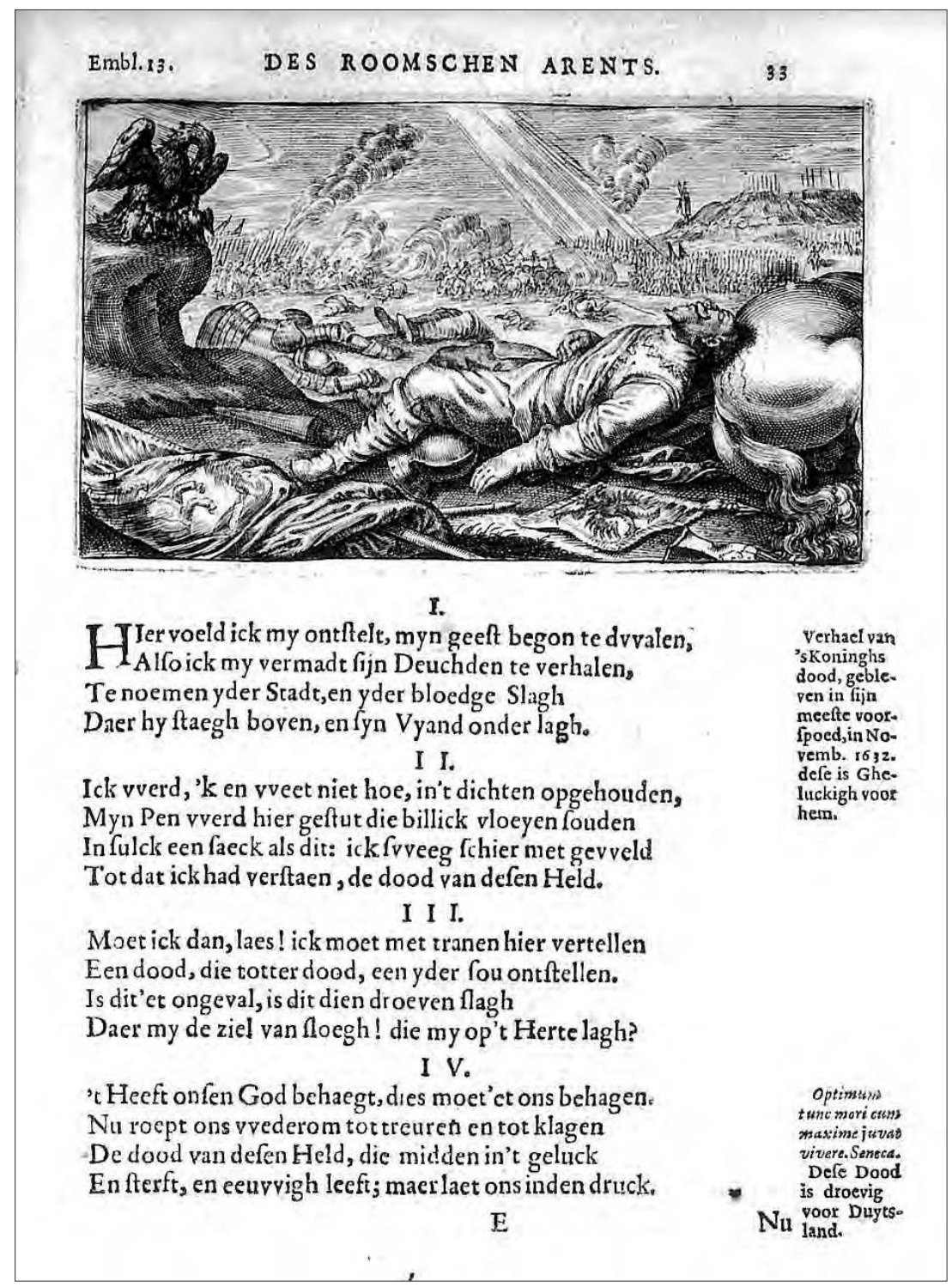

Ill. 3: Den onderganck des Roomschen Arents (La Haye, Koninklijke Bibliothek). 


\section{Dank dem Retter der Freiheit!}

À la fin de la guerre et pendant une assez longue période, il n'a plus guère été question de Gustave Adolphe en Allemagne, alors que, de manière compréhensible, son renom est resté important en Suède: il fut le modèle guerrier de Charles XII, mais la mort de celui-ci marqua la fin de la période de grande puissance (Stormaktstiden) de la Suède, et si Gustave III se revendiqua à nouveau de son illustre prédécesseur, c'est dorénavant à titre de "grand ancêtre» (c'est l'époque où on lui éleva des statues à Stockholm et à Göteborg). Il est devenu un héros national suédois, sans grandes références à son action dans l'Empire, sauf, comme on le verra, en réaction aux célébrations entreprises en Allemagne à partir des années 1840, en un lieu de mémoire qui allait rapprocher les deux nations: Lützen ${ }^{(15)}$.

Dans le contexte allemand, outre quelques gravures d'art populaire du début du $\mathrm{XVIII}^{\mathrm{e}}$ siècle, dont il sera question plus loin, il faut tout de même noter un renouveau d'intérêt pour le roi de Suède vers la fin du siècle, grâce notamment à l'Histoire de la guerre de Trente Ans de Schiller, publiée en 1791, où l'écrivain, malgré sa sympathie évidente, affirme que la mort du roi arrivait au moment où le retournement en faveur des protestants était devenu irrésistible et que son décès était le dernier service qu'il avait rendu à l'Allemagne.

Plus intéressants pour notre propos sont les deux poèmes de jeunesse de Hölderlin consacrés à Gustave Adolphe, datant de 1789 et non publiés à l'époque. S'ils n'ajoutent pas grand-chose à sa gloire littéraire, ils n'en sont pas moins représentatifs, dans leur enthousiasme Sturm und Drang, de ce que pouvait retenir la jeunesse luthérienne de l'époque de cette guerre. Il faudrait pouvoir citer l'intégralité des deux poèmes ${ }^{(16)}$, d'un pathos extraordinaire; on en jugera par exemple par les premiers vers:

«Gustav Adolf

Kommt, ihr Kinder von Teut!

Ihr Kinder von Teut! zum Tale der Schlacht

Entblößet die Häupter, ihr Kinder von Teut!

Und schauet nieder mit heiligem Blick!

Denn hier - hier starb der Mann ${ }^{(17)}$.

Au milieu du poème est évoqué le personnage du «traître», reprenant une légende propagée, semble-t-il, assez rapidement après la bataille par les Suédois et selon laquelle le roi aurait été tué par derrière par un de ceux qui l'accompagnaient, le duc Franz Albrecht de Saxe-Lauenbourg, personnage en effet assez douteux qui a

15 Il ne semble pas qu'en 1813, peu avant la bataille de Leipzig, le roi de Suède Charles XIV Jean, pourtant vainqueur d'Oudinot à Großbeeren, tout près de Lützen et non loin de Breitenfeld, ait eu l'idée de commémorer quoi que ce soit. Mais il est vrai que le Français Bernadotte n’était Suédois que depuis peu!

16 Voir Jochen Sснміdт (éd.), Friedrich Hölderlin. Sämtliche Gedichte, Francfort-sur-le-Main, Deutscher Klassiker Verlag, 2005, p. 75-79 et commentaires p. 542-545.

17 («Approchez, enfants de Teut!/ Vous, enfants de Teut! dans la vallée du combat/ Découvrez vos têtes, enfants de Teut / Et contemplez avec un regard saint! / Car c'est ici - ici que mourut l'homme.») Depuis le XVI ${ }^{\mathrm{e}}$ siècle, Teut était l'ancêtre mythique des Germains. D’autre part, la bataille de Lützen s'est déroulée dans une plaine et non dans une vallée, mais il s'agit évidemment d’une métaphore, qui fait probablement allusion à la "vallée de l'ombre de la mort» du Psaume 23,4; ce psaume est souvent interprété comme la promesse de la vie éternelle auprès du «Bon Berger». 
continuellement changé de camp, mais dont on sait depuis assez longtemps qu'il n'était pour rien dans la mort du monarque. Il est arrivé souvent dans l'histoire, quand on ne voulait pas admettre qu'un héros ait pu mourir de mort «naturelle», fût-elle guerrière, qu'on accuse un bouc émissaire. Pour rester dans notre période, quand Bernard de Saxe-Weimar, celui qui parvint à galvaniser l'armée suédoise à Lützen malgré la mort du roi et réussit en 1639 à prendre aux Impériaux la forteresse de Breisach sur le Rhin, mourut peu de temps après d'une forte fièvre, on accusa Richelieu, son "employeur» de l'avoir fait empoisonner pour garder Breisach et contrôler l'Alsace, dont Bernard espérait faire son duché; mais il semble là encore que c'était faux.

Vient ensuite la longue liste des remerciements au sauveur de la liberté (c'est le premier vers qui m’a donné le titre de cette partie), à celui qui a vaincu tant de fois, au juge des assassins de la veuve et des faibles, à celui qui a séché les larmes des martyrs, à celui, pour résumer, qui a mené le bon combat, le tout ponctué de O Gustav! Gustav!, interjections qui reviennent encore dans le second poème, qui se divise en fait en un poème classique suivi d'une ode inspirée formellement par Klopstock. Le ton devient cosmique et apocalyptique: au jour du Jugement, Jehovah (sic), qui accable les ennemis des «leçons de ma bouche», des "enfants de mon Luther», proclame à l'intention de Gustave Adolphe: «Dein Lohn sei herrlich! du Gesegneter!» (Que ta récompense soit splendide! toi qui est Béni!).

En 1882 encore, dans sa nouvelle Gustav Adolfs Page, l'écrivain suisse ConradFerdinand Meyer reprend, de façon au moins suggérée, la thèse du complot infernal, le prince de Saxe-Lauenbourg étant comparé au démon; mais c'est surtout les nombreuses comparaisons du roi au Christ qui rythment ce récit: la scène où il rudoie les princes allemands pillards fait penser au Christ chassant les marchands du temple, par ailleurs motif ancien de la propagande antipapiste, et l'auteur fait explicitement le rapprochement avec Jésus entrant à Jérusalem lors de l'entrée de Gustave Adolphe à Naumburg, où la foule l'acclame, dans la mesure où, dans les deux cas, la mort est proche. Enfin, si Meyer imagine que le page Leubelfing, personnage historique mortellement blessé dans la bataille aux côtés du roi, était en fait une jeune fille déguisée, c'est très probablement pour faire la comparaison avec Marie-Madeleine.

En considérant maintenant la production artistique sur le sujet, on s'aperçoit qu'en Suède comme en Allemagne, le XIX ${ }^{\mathrm{e}}$ siècle, principalement à partir des années 1840, a produit de très nombreuses peintures, dessins et gravures qui exaltent le personnage du roi, en le montrant principalement en chef de guerre, sa mort à Lützen étant très souvent représentée. L'objectif de la peinture d'histoire de l'époque était de le montrer en «grand homme», comme ce fut le cas pour Frédéric II par exemple, plutôt que d'insister sur sa fonction de sauveur du protestantisme allemand ${ }^{(18)}$. Toutefois il

18 On trouvera chez Siegfried Müller, «Der Dreißigjährige Krieg in der deutschen Historien- und Genremalerei des 19. Jahrhunderts», Zeitschrift für Kunstgeschichte, 1 (1999), p. 1-27, des analyses détaillées à ce sujet, ainsi que, pour l’art suédois, Allan Ellenius, "Gustav Adolf i bildkonsten: från Miles Christianus till nationell frihetssymbol» (Gustave Adolphe et les beaux-arts: du Miles christianus au symbole national de liberté), in : Kersti HoLmQUist (dir.), Gustav II. Adolf - 350 år efter Lützen, Stockholm, Livrustkammaren, 1982, p. 91-111. 
y a eu à plusieurs reprises, notamment dans l'art populaire, des références explicites à ce dernier aspect.

On peut même trouver parfois des allusions christiques: en 1843, un peintre munichois, H. Glindemann, dont on ne connaît rien par ailleurs, réalise La mort de Gustave Adolphe dans la bataille de Lützen, en visualisant la narration dramatique de Schiller ${ }^{(19)}$, mais il substitue un cheval blanc au véritable cheval brun du roi, nommé Streiff et qui, gravement blessé, a été naturalisé et figure dans une vitrine de la Livrustkammaren (salle d'armes devenue un musée) du palais royal de Stockholm. Or, dans le symbolisme chrétien, le Christ est parfois représenté comme un cavalier chevauchant un cheval blanc, en référence à Apocalypse 19,11: "Alors je vis le ciel ouvert, et un cheval blanc apparut. Celui qui le monte s'appelle Fidèle et Vrai, il juge et fait la guerre avec justice ${ }^{(20)}$. Sachant que ce passage fait notamment référence à II Mac. 3,25 et 11,8 et que Gustave Adolphe a été très souvent comparé à Judas Maccabée, on ne peut guère douter de l'intention de l'artiste.

Peut-être est-ce surtout dans le contexte plus large de l'art populaire que ce renouveau est le plus palpable: des gravures parfois coloriées et visiblement destinées à être fixées au mur font leur apparition à partir de ces années 1840. Éditées à Berlin, à Francfort et à Wissembourg (cette dernière sans doute destinée principalement aux luthériens alsaciens), elles s'intitulent Der Fels der Kirche (Le rocher de l'Église) et diffèrent relativement peu entre elles, comme on va le voir (ill. 4) ${ }^{(21)}$. Dans les différentes versions ${ }^{(22)}$, on trouve quatre personnages identiques, une table d'autel au milieu, sur laquelle trônent un calice et une patène entre un crucifix ${ }^{(23)}$, qui se détache au milieu d'un énorme rocher sur le sommet duquel se dresse une église, dont les deux tours sont reliées, dans deux des images, par l'œil de Dieu inscrit dans le triangle trinitaire. Sur l'antependium figure une fois encore le premier vers du "cantique de Luther»: Eine feste Burg ist unser Gott, qui verbalise l'église fortifiée qui couronne la représentation et qui est entourée de deux quatrains, dont je traduis simplement le premier vers du second, qui donne le ton : "Le rocher de l'Église, fondé sur la Parole de Dieu». Il y a sans doute là aussi une allusion à la Jérusalem céleste, même s'il fallait là les explications d'un pasteur.

19 Friedrich Schiller, Geschichte des Dreißigjährigen Kriegs, in: Karl-Heinz Ha Hn (éd.), Schillers Werke Nationalausgabe, Bd. 18: Historische Schriften, Zweiter Teil, Weimar, 1973, p. 270 sqq.

20 Voir à ce sujet, S. Müller, «Der Dreißigjährige Krieg in der deutschen Historien- und Genremalerei des 19. Jahrhunderts» (note 18), p. 11.

21 Voir l'article sur ce sujet de Gerhard Seib, "Gustav Adolf und “Der Fels der Kirche" - Zu einer Populärgrafik des 19. Jahrhunderts", in: Gustav Adolf, König von Schweden. Die Kraft der Erinnerung 1632-2007, Lützen, Museum Schloß Lützen, 2007, catalogue sous la dir. de Maik ReICHEL et Inger Schuberth, Dößel, J. Stekovics Verlag, 2007, p. 153-158.

22 J'ai choisi ici la $3^{\mathrm{e}}$ version analysée par G. Seib (note précédente) pour la qualité de la reproduction, mais elle ne diffère qu'assez peu des autres.

23 Le crucifix, absent en milieu réformé, signifie qu'on s'adresse en premier lieu aux luthériens, mais les rapprochements entre les deux confessions à partir du début du XIX ${ }^{\mathrm{e}}$ siècle font que ce sont les protestants dans leur ensemble qui pouvaient se sentir concernés, d'autant qu'en pays réformé, en Palatinat ou en Hesse-Kassel par exemple, on devait se souvenir que l'emprise du catholicisme militant avait pu être arrêtée par l'intervention suédoise, les princes concernés ayant été les premiers alliés allemands du roi. 


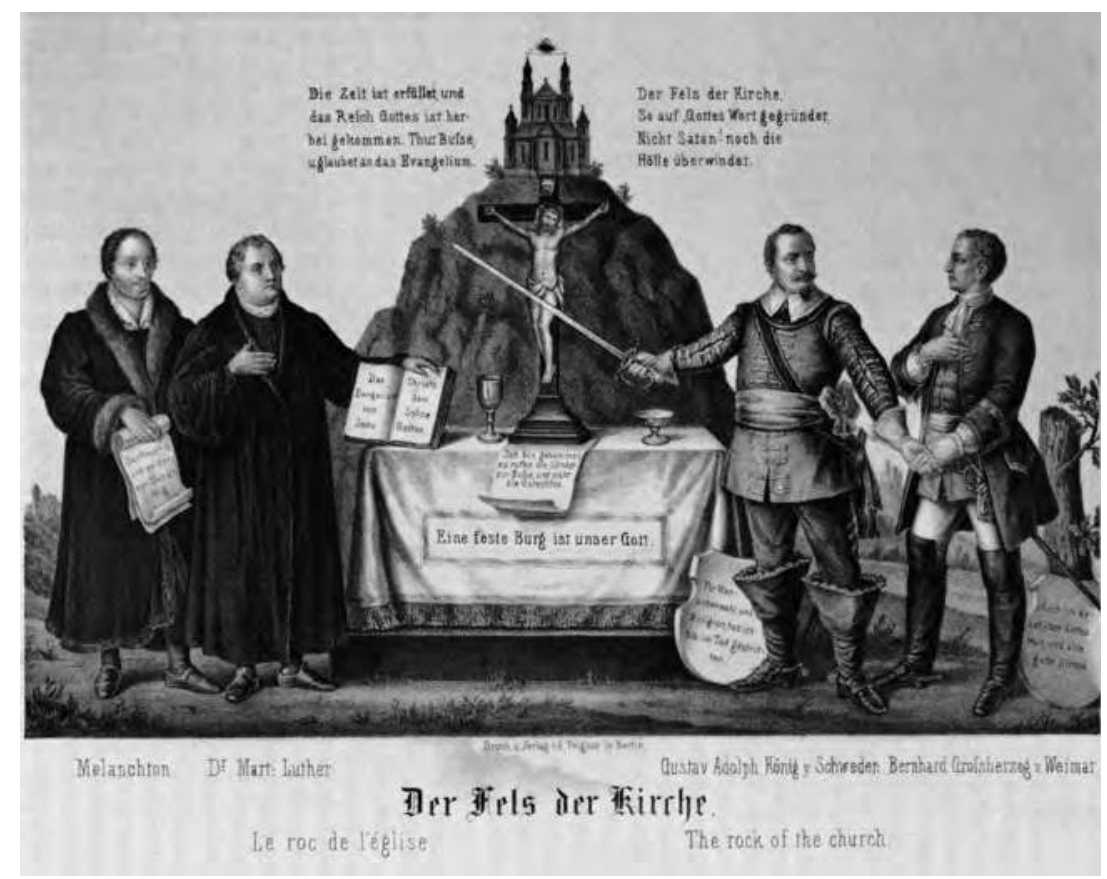

Ill. 4: Der Fels der Kirche (Archives de l'auteur).

Pour en venir aux personnages, ils sont regroupés deux par deux: du côté gauche (mais à droite du Christ, comme dans les représentations médiévales de la Crucifixion), on trouve Luther et Mélanchthon, les «rénovateurs» de l'Église, Luther tenant, comme dans de nombreuses représentations des débuts de la Réforme, un livre ouvert, qui est évidemment la Bible et plus particulièrement le Nouveau Testament, résumé par la phrase «Das Evangelium von Jesu Christo dem Sohne Gottes » (L'Évangile de Jésus-Christ, le Fils de Dieu) ${ }^{(24)}$. Du côté droit se tient dans une attitude martiale Gustave Adolphe, au pied duquel un écriteau en forme de bouclier proclame: «Für Menschenwohl und Religion, hab ich bis in den Tod gestritten » (J'ai combattu jusqu'à la mort pour le bien des hommes et pour la religion), les deux autres versions disant pratiquement la même chose. À côté de lui se trouve un personnage qui est désigné dans toutes les versions comme Bernard de Saxe-Weimar, mais qui est en réalité Charles XII ${ }^{(25)}$, assez reconnaissable, ne serait-ce que par son uniforme, typique des débuts du XVIII ${ }^{\mathrm{e}}$ siècle, du moins dans cette version. Même s'il avait en effet réussi, par la Convention d'Altrandstädt (1707), à contraindre l'empereur à rendre au culte protestant les églises silésiennes recatholicisées au mépris des stipulations des traités de Westphalie, on ne peut guère présenter Charles XII comme un héros du protestantisme. Et pourtant ce fut le cas si l'on en croit deux

24 Allusion évidente au christocentrisme luthérien, les protestants allemands sachant naturellement que Luther avait traduit en premier le Nouveau Testament.

25 Même G. SEIB, «Gustav Adolf und "Der Fels der Kirche” » (note 21), fait la confusion... 
gravures presque identiques, qui ont inspiré une peinture sur verre, le tout devant dater des années immédiatement postérieures à la Convention en question. Elles sont clairement à l'origine des images du $\mathrm{XIX}^{\mathrm{e}}$ siècle $^{(26)}$. Luther y figure de façon originale, comme image sur la page droite d'un livre ouvert, la Bible évidemment, devant le crucifix, dans une des gravures, alors que dans l'autre il est attablé à sa table de travail (certainement encore pour la traduction du Nouveau Testament) dans une vignette insérée au milieu des écus portant à peu près les mêmes paroles que dans les versions du XIX ${ }^{\mathrm{e}}$ siècle. Mais il n'y a que deux personnages représentés en pied, Gustave Adolphe et Charles XII, chacun d'eux portant un bâton de commandement, et d'autre part il n'y a plus d'autel, le crucifix se détachant au milieu du rocher audessus du Livre et en-dessous de l'Église. Ce dernier point se comprend bien dans la mesure où les théologiens Luther et Mélanchthon sont absents, même si le premier est montré par une image dans l'image. En revanche, la présence des deux rois de Suède, dûment entourés de citations bibliques et de textes célébrant la Parole de Dieu, est moins immédiatement compréhensible au début du XVIII ${ }^{\mathrm{e}}$ siècle. Les gravures doivent certainement dater des années 1707-1708, quand Charles XII était encore au faîte de sa puissance, avant sa fatale campagne de Russie. D’autre part, alliés à l'empereur, la majorité des princes allemands protestants, après avoir accueilli les réfugiés français à la suite de la Révocation de l'Édit de Nantes, participaient à la coalition antifrançaise de la guerre de Succession d'Espagne, qui n'avait rien d'une guerre de religion. Certains milieux protestants des villes libres, qui avaient beaucoup perdu de leur pouvoir politique et où furent évidemment confectionnées ces images, se demandaient-ils s'il ne faudrait pas un jour refaire appel au dirigeant du pays qui avait sauvé le protestantisme allemand, Charles XII ayant explicitement pris modèle sur son prédécesseur ${ }^{(27)}$ ?

\section{Une exposition et ses enjeux}

Le propos de mon article doit beaucoup à la remarquable exposition qui a eu lieu à Lützen en 2007, pour le $475^{\mathrm{e}}$ anniversaire de la mort de Gustave Adolphe. Elle se proposait d'examiner différentes facettes de la mémoire du roi et de déterminer s'il fut bien un "Christ und Held», selon les termes de ce qui a sans doute été la dernière biographie de ce type, l'ouvrage de Johannes Paul, publié en 1932 et tout imprégné de ce que Günter Barudio, plus récemment, qualifiait très justement de «Deutschtümelei» nationaliste.

Intitulée Gustav Adolf, König von Schweden. Die Kraft der Erinnerung 1632-2007 ${ }^{(28)}$, cette exposition expressément commémorative, comme l'indique son sous-titre, se voulait aussi une réflexion sur la façon dont les différentes époques jusqu'à nos jours ont perçu le rôle du roi dans ses dimensions politiques et religieuses; le sous-titre reste d'ailleurs volontairement neutre à ce sujet. Fruit d'une collaboration étroite entre la

26 Voir repr. et commentaires chez G. SEIB, ibid., p. 156-158.

27 Comme l'expriment les paroles qui lui sont attribuées sur l'écu devant lui: «Ich folg Gustavo nach in seinen Tugendt [und] Sitten» (Je suis Gustave dans ses vertus et ses mœurs), phrase reprise dans les versions du XIX ${ }^{\mathrm{e}}$ siècle.

Voir la référence du catalogue en note 21. 
ville de Lützen et la Lützenstiftung de Göteborg, l'exposition a pu bénéficier, outre les fonds importants de ces deux institutions, de pièces exceptionnelles venant de la Livrustkammaren de Stockholm; citons aussi celles issues de l'ancienne et remarquable collection d'Oskar Planer (1853-1931), citoyen de Lützen passionné par Gustave Adolphe, conservée aujourd'hui à la Bibliothèque universitaire d'Uppsala. Logée dans quelques pièces du petit château de Lützen, où Wallenstein a d'ailleurs passé les deux nuits avant la bataille (avant de faire mettre le feu à la ville pour gêner l'ennemi...), l'exposition était très bien conçue et mise en scène. Outre de nombreux tableaux, statuettes, gravures et objets d'art représentant le roi, la grande vitrine contenant les armes et les vêtements tachés de sang du roi en constituait évidemment le nœud central, forme contemporaine et luthérienne du reliquaire. On peut noter à ce propos que, quelques années auparavant, le roi avait fait envoyer à Stockholm des vêtements ensanglantés qu'il portait lors d'une bataille en Prusse en mai 1527 contre les Polonais ${ }^{(29)}$, pour, ainsi qu'il a été noté plus tard, en garder «mémoire éternelle». Même si la Livrustkammaren existait depuis assez longtemps, ce don constitua la pièce inaugurale du premier musée suédois ${ }^{(30)}$. Les vêtements tachés de sang portés par le roi à Lützen, dont des soldats ennemis l'avaient dépouillé, sans d'ailleurs qu'ils sachent dans l'immédiat de qui il s'agissait, ont plus tard été reconnus comme étant ceux du roi et conservés ensuite comme «trophées» à Vienne. Ce n'est qu'en 1920 que le gouvernement autrichien, reconnaissant à la Croix-Rouge suédoise de son soutien pendant la guerre et dans les mois de misère d'après 1918, les a rendus à ce pays.

Mais l'exposition s'insérait dans un contexte plus large, d'abord parce qu'une imposante statue en pied du roi orne l'angle principal de l'hôtel de ville, constituant ainsi la figure tutélaire de la cité, ensuite et surtout parce qu'à la sortie nord-ouest, dans la direction de Leipzig, là même où s'est déroulée la bataille, se dresse un ensemble de constructions appelée la «Schwedeninsel», groupées autour de la chapelle commémorative.

Tout part d'une grosse pierre, trouvée sur le champ de bataille à l'endroit supposé de la mort du roi, et nommée depuis lors le «Schwedenstein», pierre sur laquelle fut apposée le monogramme du roi et la date de 1632 et qui très vite a attiré des pèlerins. C'est en 1832, lors de la commémoration du deuxième centenaire de la bataille, que fut décidée l'érection d'un monument incluant cette pierre; Karl Friedrich Schinkel, le grand architecte prussien de l'époque, était le concepteur d'un baldaquin néogothique en fonte orné de citations bibliques, qui fut inauguré en 1837. On notera aussi que c'est dans ce contexte de renouveau du souvenir que fut fondé également en 1832 le

29 Barbro Bursell, Zum Gedächtnis eines Königs. Gustav II. Adolf und die königliche Rüstkammer, Stockholm, Livrustkammaren, 2007, p. 24-25, fait remarquer que c'était aussi une manière pour le roi d'affirmer sa légitimité vis-à-vis de la branche polonaise des Vasa, que son père Charles IX avait déjà dû combattre.

30 Dans un esprit analogue, le roi de Danemark Christian IV, blessé et ayant perdu un œil dans la bataille navale de Kolberger Heide contre la flotte suédoise en 1644, fit faire des boucles d'oreille à partir de deux éclats de métal qui l'avaient atteint et en fit présent à sa maîtresse, Vibeke Kruse. Cette parure est toujours conservée au château de Rosenborg à Copenhague (voir le catalogue Christian IV and Europe, Copenhague, 1988, p. 177, n 633). Il y a pourtant une différence de taille: dans ce dernier cas, on reste dans le domaine privé. 
Gustav-Adolf-Verein, qui existe toujours sous le nom de Gustav-Adolf-Werk et qui était destiné à soutenir les minorités protestantes, où qu'elles soient ${ }^{(31)}$. Puis, après plusieurs projets dans la seconde moitié du XIX ${ }^{\mathrm{e}}$ siècle, ce fut un mécène suédois, le consul Oscar Ekman, qui fit construire une chapelle commémorative "dans le style suédois» par un jeune architecte, Lars Wahlman (ill. 5). La première pierre fut posée le 6 novembre 1906 et l'inauguration, à laquelle assistèrent notamment des représentants de tous les régiments suédois ayant participé à la bataille, eut lieu le 6 novembre 1907. Vint s'y ajouter dans les années trente une petite maison en bois peint, suivie d'une autre dans les années soixante.

La chapelle est un monument très évocateur, statues, monogrammes et armoiries de Gustave Adolphe étant omniprésentes. Elle est d'une architecture puissante, pesante même, très différente des bâtiments ecclésiaux habituels en Allemagne. L'intérieur, à plafond de bois, évoque un peu un navire et conserve, outre des vitraux aux armoiries des nobles suédois, finlandais, allemands et anglais ayant servi sous le règne du roi, un imposant triptyque peint placé au-dessus du maître-autel et représentant dans sa partie centrale des angelots surplombant la représentation de la bataille au loin, et sur les volets extérieurs les portraits en pied de Luther à droite et de Gustave Adolphe à gauche, les deux «quasi-saints» du luthéranisme (ill. 6). Sous le triptyque est marquée en suédois la phrase initiale du choral de bataille du roi, probablement dû à l'aumônier du roi, Fabricius, et censé avoir été chanté le matin de Lützen: Verzage nicht, du Häuflein klein (Ne perds pas courage, petit troupeau). Ce choral a joui d'une grande popularité dans le luthéranisme (Bach a par exemple utilisé la première strophe dans

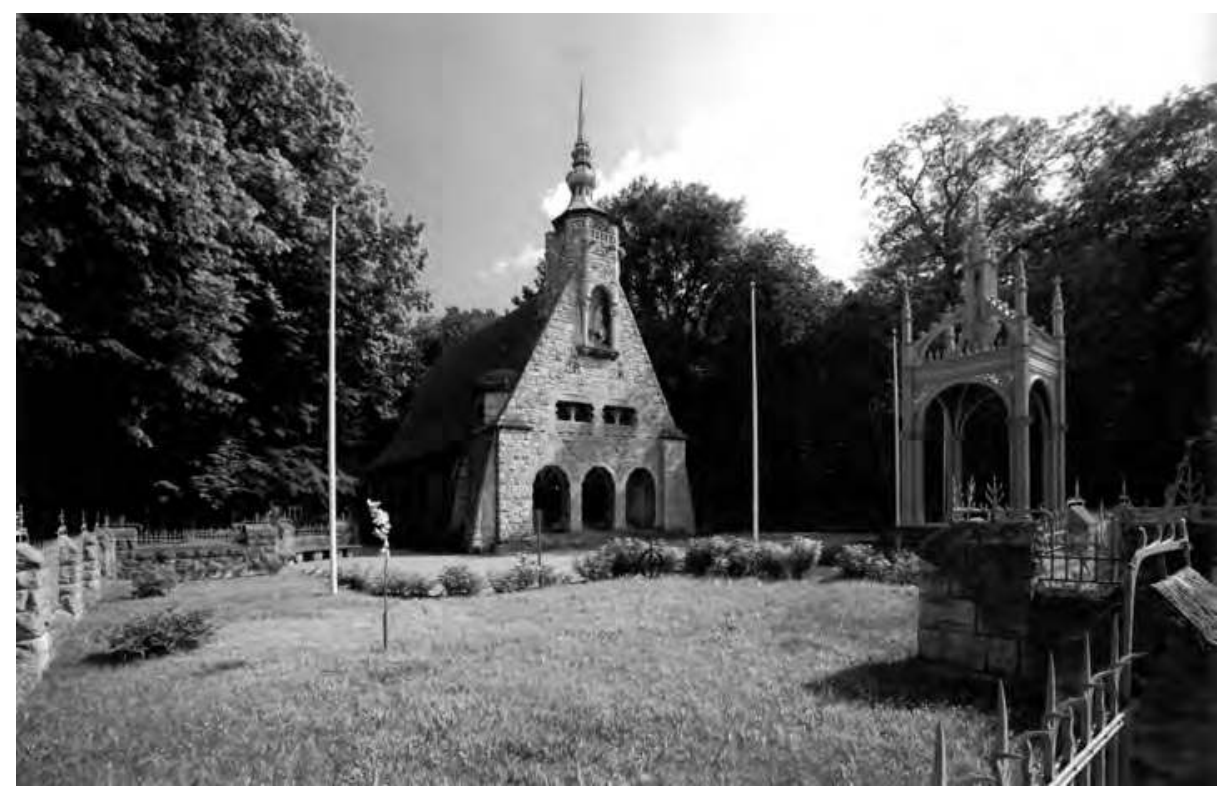

Ill. 5: Chapelle commémorative de Lützen (Archives de l'auteur).

31 Voir, sur ce sujet, les articles du catalogue cité en note 21, p. 137-152. 
la cantate BWV 32) et continue à être chanté. On pourrait dire que c'est un peu le pendant du célèbre choral de Luther, Eine feste Burg ist unser Gott (C'est un rempart que notre Dieu), joignant ainsi par la "parole» les deux personnages, Luther ayant "apporté» la Réforme à la Suède, alors que Gustave Adolphe l'a sauvée par son intervention en Allemagne.

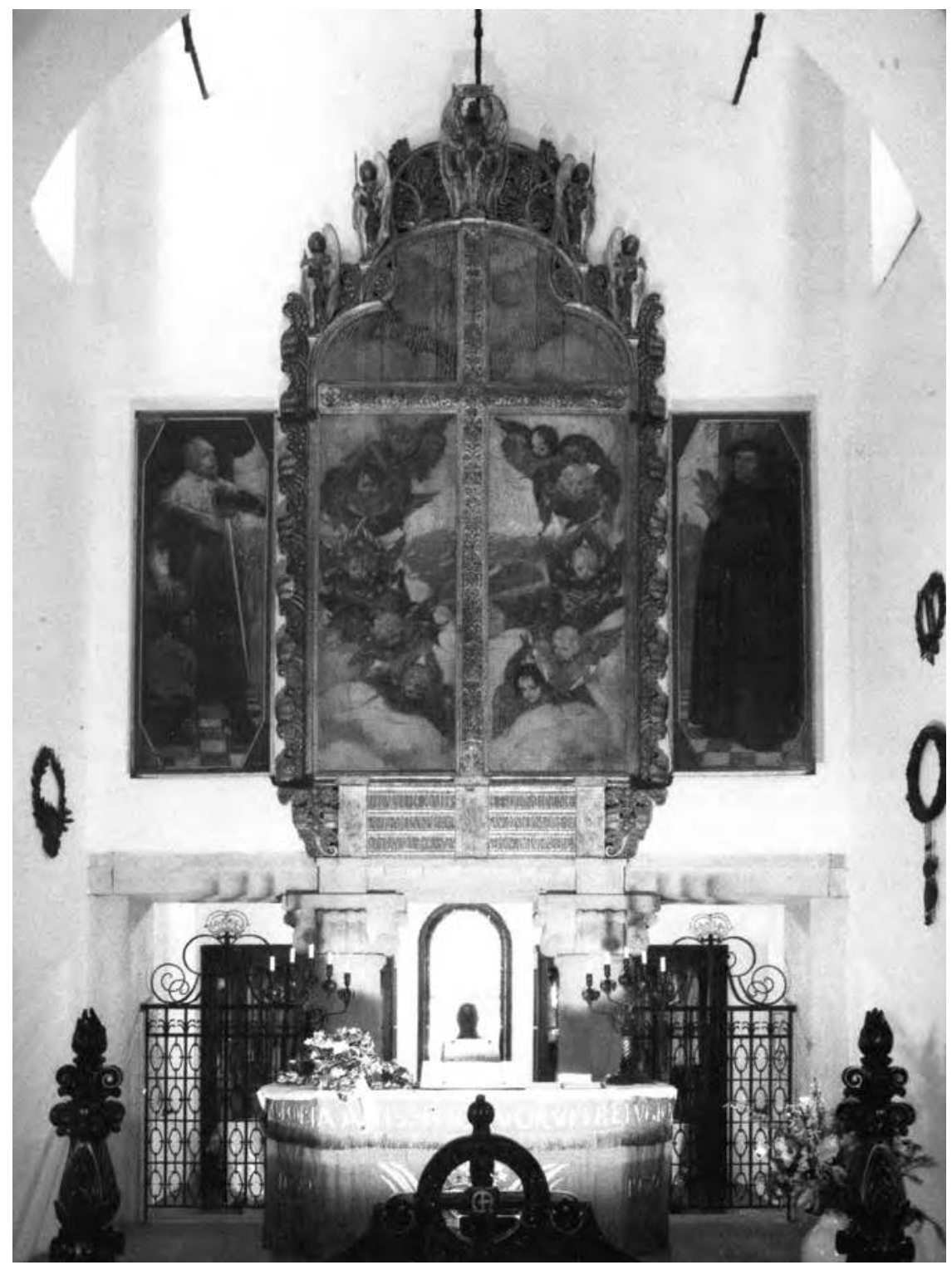

Ill. 6: Triptyque à l'intérieur de la chapelle (Archives de l'auteur). 


\section{Bibliographie}

NB: La bibliographie sur Gustave Adolphe étant pléthorique, je n’indique ici que les sources et ouvrages que j'ai consultés principalement.

Günter BARudio, Gustav Adolf - der Große. Eine politische Biographie, Francfort-sur-le-Main, Fischer Taschenbuch Verlag, 1985 (2 éd.).

Günter Barudio, Der Teutsche Krieg 1618-1648, Francfort-sur-le-Main, Fischer Verlag, 1985.

Johannes Burkhardt, Der Dreißigjährige Krieg, Francfort-sur-le-Main, Suhrkamp, 1992.

Barbro Bursell, Zum Gedächtnis eines Königs. Gustav II. Adolf und die königliche Rüstkammer, Stockholm, Livrustkammaren, 2007.

Uwe Gerig, Lützen, Königstein, Ruth Gerig Verlag, 1994.

Wolfgang Harms (éd.), Deutsche illustrierte Flugblätter des 16. und 17. Jahrhunderts II: Die Sammlung der Herzog August Bibliothek in Wolfenbüttel, Bd. 2: Historica, Munich, Verlag Kraus, 1980.

Wolfgang Harms (éd.), Deutsche illustrierte Flugblätter des 16. und 17. Jahrhunderts IV: Die Sammlung der Hessischen Landes- und Hochschulbibliothek in Darmstadt, Tübingen, Niemeyer, 1987.

John Roger PAas (éd.), The German Political Broadsheet 1600-1700, vol. 5: 1630-1631, Wiesbaden, Harrassowitz, 1996; vol. 6: 1632, Wiesbaden, 1998; vol. 7: 1633-1648, Wiesbaden, 2002.

Maik Reichel, Inger Schuberth (éd.), Gustav Adolf, König von Schweden. Die Kraft der Erinnerung 1632-2007, cat. d'exp. Museum Schloß Lützen, Dößel, Verlag Janos Stekovics, 2007.

Silvia Serena Tsсноре, Heilgeschichtliche Deutungsmuster in der Publizistik des Dreißigjähriges Krieges, Berne/Francfort-sur-le-Main, Peter Lang (Mikrokosmos, vol. 29), 1991.

Andreas WANG, Der "miles christianus» im 16. und 17. Jahrhundert und seine mittelalterliche Tradition, Berne/Francfort-sur-le-Main, Peter Lang (Mikrokosmos, vol. 1), 1975.

\section{Résumé}

Dès son débarquement en Allemagne, le roi de Suède Gustave Adolphe a été présenté par la propagande protestante comme l'envoyé du Très-Haut pour sauver le protestantisme allemand, en l'insérant dans une histoire du salut quelque peu laïcisée. Une vague d'écrits et de feuilles volantes illustrées accompagne sa campagne victorieuse. Après sa mort, l'accent va être mis sur son sacrifice et la comparaison avec le sacrifice du Christ apparaît même quelquefois. On affirme aussi que symboliquement il n'est pas mort et qu'il doit continuer d'inspirer la lutte contre "l'Antéchrist». Après une relative éclipse au XVIII siècle, son souvenir est à nouveau fortement affirmé en Allemagne, sur le lieu de sa mort à Lützen, principalement à partir du 200 anniversaire de sa mort en 1832, et au début $d u X^{e}$ siècle, une chapelle à sa mémoire sera construite à cet endroit, associant, comme ce fut souvent le cas dès le début, le souvenir du roi à celui de Luther.

\section{Zusammenfassung}

Schon gleich nach seiner Landung hat die protestantische Propaganda den König von Schweden, Gustav Adolf, als Gottes Abgesandten, um den deutschen Protestantismus $z u$ retten, dargestellt. Er wurde in einer Reihe biblische Helden hineingegliedert und so in einer ein wenig verweltlichten Heilsgeschichte eingesetzt. Sein siegreicher Feldzug war von einer Flut von Schriften und Flugblätter begleitet. Sein Tod wurde als Opfertod dargestellt und mehrmals mit Christis Opfer verglichen. Man schrieb auch, daß er 
symbolisch noch lebte und daß man ihn als Vorbild nehmen sollte in dem Kampf gegen den "Antichrist“. Nach relativer Verdunkelung im 18. Jahrhundert wurde im 19. Jahrhundert sein Andenken in Deutschland wieder stark bestätigt und das hauptsächlich in Lützen, wo er den Tod fand. In 1832 wurden die 200 Jahren nach seinem Tod feierlich begangen, und anfangs des 20. Jahrhunderts baute man an der Stelle der Schlacht eine Gedächtniskapelle, wo man Gustav Adolfs Erinnerung mit derer Luther vereinigte. 